\title{
Adoption and Factors Affecting Farmer's Adoption of Technologies in Farming System: A Case Study of Improved Technologies in ICARDA's Arabian Peninsula Regional Program
}

\author{
Boubaker Dhehibi ${ }^{1}$, Arash Nejatian ${ }^{2}$, Hamdan Al-Wahaibi $^{3}$, Khader Atroosh $^{4}$, Mohamed S. Al Yafei ${ }^{5}$, Ahmed Al \\ Otaibi $^{6}$, Mohamed Al Hendi ${ }^{7}$ \& Azaiez Ouled Belgacem ${ }^{2}$ \\ ${ }^{1}$ Sustainable Intensification and Resilient Production Systems Program - SIRPS, International Center for \\ Agricultural Research in the Dry Areas (ICARDA), Amman, Jordan \\ ${ }^{2}$ ICARDA Arabian Regional Program (APRP), International Center for Agricultural Research in the Dry Areas \\ (ICARDA), Dubai, UAE \\ ${ }^{3}$ Ministry of Agriculture and Fisheries, Oman \\ ${ }^{4}$ Agricultural Research and Extension Authority (AREA), Yemen \\ ${ }^{5}$ Ministry of Municipality and Environment, Qatar \\ ${ }^{6}$ Ministry of Agriculture, KSA \\ ${ }^{7}$ Minsitry of Municipalities Affairs and Urban Planning, Bahrain \\ Correspondence: Boubaker Dhehibi, Sustainable Intensification and Resilient Production Systems Program, \\ International Center for Agricultural Research in the Dry Areas, P.O. Box 950764 Amman, Jordan. Tel: \\ 962-06-590-3120-139. E-mail: b.dhehibi@cgiar.org
}

Received: May 21, 2017

doi:10.5539/jsd.v10n6p1
Accepted: June 22, $2017 \quad$ Online Published: October 5, 2017

URL: https://doi.org/10.5539/jsd.v10n6p1

\begin{abstract}
The main objective of this study is to assess the rate of adoption of innovations introduced by the Arabian Peninsula Regional Program (APRP) of ICARDA and identify main constraints that limit the adoption process of these new technologies in the GCC countries and Yemen through using ADOPT (Adoption and Diffusion Outcome Prediction Tool). ADOPT predicts the proportion of a target population that might adopt an innovation over time. A focus group discussion (FGD) methodology was used to apply the ADOPT with a panel of farmers in each country and for each introduced technology. In the FGD we streamlined 22 discussion questions around four categories of influences on adoption: characteristics of the innovation, characteristics of the target population, the relative advantage of using the innovation, and learning of the relative benefit of the change.
\end{abstract}

The results showed that predicted peak of adoption and time for reaching that peak vary between technologies, countries, and within the same country. The technology specific variables (e.g. yield potential and acceptability) are significant for explaining adoption behavior, implying that it is important to take farmers' preferences to varietal characteristics into consideration in the design of a research and development program. Given the significant role played by extension and access related variables, increased emphasis on information dissemination, field demonstration, and farmers' participatory research and training programs to popularize these technologies and enhance their adoption rate are required. This also suggests that policy intervention should be made on improving the knowledge status of farming households, and developing programs on the technological package which offer farmers a variety of choices among the appropriate pools of technology options. Such programs ultimately help farmers to develop more profit-oriented behavior (both economically and environmentally) which are necessary to enhance adoption rate, production, and food security in the long run for the GCC countries and Yemen.

Keywords: adoption, APRP-ICARDA technologies, diffusion, GCC, prediction, Yemen

\section{Introduction}

Because of the aridity prevailing in most of the Middle East and North Africa Countries, the Arabian Peninsula (AP) is the poorest in the world regarding water resources, both globally and per inhabitant. Arid conditions in 
these countries act as a natural constraint for expansive agriculture (Mazahrih et al., 2016). Only $1.7 \%$ of the total land area is arable in GCC countries. As a result, $60-80 \%$ of total food demand is currently met from external sources (NCB Capital, 2010). The agriculture contributes only around 1\% - 4\% of the GCC countries' GDP as compared to $10 \%-20 \%$ for their emerging market counterparts (NCB Capital, 2010). Moreover, rapidly growing populations and rising per capita consumption becomes the key drivers for growth in food consumption. Indeed, increasing income levels and rising prosperity are leading to a shift in food consumption patterns with the demand for food products growing fast and contributing to more intensive land use.

The scarcity of arable land and water have limited the growth of AP agriculture. With the limited potential for farming sector, optimizing the utilization of these limited resources for technology transfer in agricultural development is one of the biggest challenges facing any decision-maker including the end users and growers. Thus, developing a sustainable and improved agriculture system would have a significant impact on helping these countries to shift their agricultural priorities from self-sufficiency to food security.

Upon the request from the AP National Agricultural Research Systems (NARS), the International Center for Agricultural Research in the Dry Areas (ICARDA) has developed a program for the region known as the Arabian Peninsula Regional Program (APRP) since 1995. The program aims, through the development and enhance technologies, to improve the agriculture productivity and contribute to reducing the food production gap. As the AP region, already among the largest food importers, is set to witness a significant growth in import of food products in the coming years. Several proven and improved technologies packages for the different production systems have shown their evidence at the research station such as protected agriculture and its associated techniques, irrigated forages, on-farm water management, spineless cactus, and rangeland rehabilitation. However, some of these technologies are not widely adopted. While developing improved technologies is important for farmers in the rural areas, new technologies can only affect livelihoods positively if they are profitable and by then adopted by farmers.

On the light of these challenges, and to enhance the adoption and accelerate its process, the objective of this paper is twofold: i) to assess the rate of adoption of these technologies and identify primary constraints that limit the adoption process in the AP countries and Yemen through using ADOPT (Adoption and Diffusion Outcome Prediction Tool), and ii) to draw recommendations to promote adoption, ensure scaling-up and widespread use of these technologies in the AP countries.

\section{Material and Methods}

\subsection{Data Collection and Data Sources}

The results of this research are based on a mainly focus groups discussions conducted with farmers and growers adopting APRP-ICARDA technologies in five among the seven Arabian Peninsula (AP) countries (Bahrain, Kuwait, Oman, Qatar, Saudi Arabia, UAE, and Yemen). Five technologies' packages were introduced by ICARDA-APRP to improve the agricultural production under the very harsh environmental conditions of the region and chosen to assess the levels and the constraints facing their adoption. They include: the soilless system in protected agriculture (Technology I); the integrated production and protection management (IPPM) in protected agriculture (Technology II); the use of native range species (Buffel grass) as irrigated forage instead of high water consuming exotic species such as Rhodes grass (Technology III); the introduction of spineless cactus with high water use efficiency (Technology IV); and the rehabilitation of rangelands using native shrubs and rain water harvesting techniques (Technology V). The data were collected using Focus Group Discussion (FGD) methodology (Krueger, 2002) to apply the ADOPT software (Kuehne et al., 2013) with different groups of farmers in the different countries. Table 1 displays the number of farmers interviewed in each country and for each technology. 
Table 1. Number of farmers interviewed in the focus group discussion in each country and for each category of technology

\begin{tabular}{|c|c|c|c|c|c|}
\hline Country / Region & $\begin{array}{c}\text { Technology I } \\
\text { Soilless Culture }\end{array}$ & $\begin{array}{c}\text { Technology II } \\
\text { IPPM }\end{array}$ & $\begin{array}{c}\text { Technology III } \\
\text { Irrigated } \\
\text { Forages }\end{array}$ & $\begin{array}{c}\text { Technology IV } \\
\text { Spineless Cactus }\end{array}$ & $\begin{array}{l}\text { Technology } \mathrm{V} \\
\text { Rangeland } \\
\text { Rehabilitation }\end{array}$ \\
\hline Bahrain & 12 & 12 & - & - & - \\
\hline KSA & 15 & 15 & 15 & - & 20 \\
\hline Qatar & 10 & - & 8 & 7 & 5 \\
\hline Yemen & 5 & 20 & 11 & - & - \\
\hline Oman - Al Dakhiliyah & 8 & - & 8 & - & - \\
\hline $\begin{array}{l}\text { Oman- North Al Batinah- } \\
\text { Sohar }\end{array}$ & 7 & - & 7 & - & - \\
\hline $\begin{array}{l}\text { Oman- North Al Batinah- } \\
\text { Al Kaborah }\end{array}$ & 7 & - & 7 & - & - \\
\hline $\begin{array}{l}\text { Oman - North Al Batinah - } \\
\text { Al Suwaq }\end{array}$ & 7 & - & 7 & - & - \\
\hline $\begin{array}{l}\text { Oman - North Al Batinah - } \\
\text { Saham }\end{array}$ & 8 & - & 8 & - & - \\
\hline
\end{tabular}

The data gathered during the FGD was used to apply the ADOPT tool. As table 1 shows, the number of farmers attending the discussion groups vary from country to another and between the targeted technologies. Twenty-two (22) discussion questions have been streamlined around four categories of influences on adoption:

- Characteristics of the innovation

- Characteristics of the target group of farmers

- Relative advantage of using the innovation

- Learning of the relative benefit of the innovation.

The format of the discussion group consisted of both analytical questions (i.e., they discuss and collectively decide what they believe the answer is), and clarifying questions (i.e., matters that help to clear up confusion and explain why they had chosen this reply). Farmers were asked to think about their problems related to implementing the targeted technologies and the most challenging for them.

\subsection{Methodological Framework: Adoption and Diffusion Outcome Prediction Tool (ADOPT)}

The use of new agricultural technologies has been found to be a function of farm and farmer characteristics and specific features of the particular technology (Feder et al., 1985; Marra and Carlson, 1987; Rahm and Huffman, 1984). A considerable set of literature has been developed regarding factors that influence the adoption of new technologies by farmers through the use of innovation theory (Feder et al., 1985; Griliches, 1957, and Rogers, 1995). Adoption and diffusion theory also have been widely used to identify the factors that influence an individual's decision to adopt or reject an innovation. Rogers (1995) defined innovation as “....an idea, practice or object that is perceived as new by an individual or other unit of adoption. The perceived newness of the idea for the individual determines his or her reaction to it." The assessment of the adoption levels including the factors affecting the adoption of the outlined technologies implemented by the project is discussed in the following section. The analysis will be based on the following five characteristics of innovation that affect an individual's adoption decision:

(i) relative advantage on how the innovation is better than existing technology;

(ii) the degree to which an innovation is seen as consistent with current experiences, needs, and beliefs of adopters (compatibility);

(iii) how difficult the innovation is to understand and use (complexity);

(iv) the degree to which the change may be utilized on a limited basis (trialability), and 
(v) the extent to which the results of innovation are visible to others (observability).

The methodological framework used in this research paper is based on the use of ADOPT (Adoption and Diffusion Outcome Prediction Tool) to predict the likely peak level of adoption of the introduced innovation by the APRP-ICARDA program and the time taken to reach that peak. The Adoption and Diffusion Outcome Prediction Tool (ADOPT) (note 1) is an MS Excel-based tool that evaluates and predicts the likely level of adoption and diffusion of specific agricultural innovations with a particular target population in mind. The ADOPT uses expertise from multiple disciplines to make the knowledge surrounding the adoption of innovations more available, understandable and applicable to researchers, extension agents and research managers. ADOPT predicts the proportion of a target population that might take a change over time. The tool makes the issues around the adoption of innovations easy to understand. ADOPT is useful for agricultural research organizations and people interested in learning how innovations are taken up. The tool has been designed to:

(i) Predict the likely peak level of adoption of an innovation and the time required to reach that peak;

(ii) Encourage users to consider the factors that affect adoption at the time that projects are designed,

(iii) Engage research, development and extension managers and practitioners by making adaptability knowledge and considerations more transparent and understandable.

This tool was used to evaluate and predict the likely level of adoption and diffusion of the improved technologies in ICARDA's Arabian Peninsula regional. ADOPT predicts the proportion of a target population that might take an innovation over time. ADOPT users respond to qualitative and quantitative questions for each of twenty-two variables influencing adoption. Going through this process also leads to increased knowledge about how the variables relate to each other, and how they affect adoption and diffusion. ADOPT is structured around four categories of influences on adoption:

Learnability of the population - Learnability of the population, concerns the characteristics of the population that affect their ability to learn about the innovation. There are four questions regarding this aspect of adoption, which focus on group involvement in the community relevant to the innovation, whether or not the populations uses advisors to get proper advice about the novelty, the relevant existing skills or knowledge in the population, and the awareness of the innovation in the society.

Learnability of the Innovation - Learnability of the innovation refers to the characteristics of the innovation itself that determine a group's ability to learn about it. Three factors are used to establish this aspect of the adoption process: capacity to run small trials of the innovation, whether or not the change requires complex changes to the farmland for implementation and the level of observation of the novelty.

Relative Advantage for the Population - Relative benefit for the community attempts to determine whether the benefit that the society could gain from the innovation is sufficient to encourage the population to adopt the change. To assess this aspect, the program asks six questions which review the following: the number of farmers that could benefit from the innovation, the extent to which farmers use long-term planning, how much the farmers' decisions are motivated by maximizing profits, how much the farmers' decisions are motivated by protecting the environment, the community's level of risk aversion, and short-term financial restraints.

Relative Advantage of the Innovation - Relative advantage of the innovation looks at the real benefits of the innovation without considering the community's perception of the innovation. This part of the process is assessed through eight questions, which deal with the following: the initial costs of implementation, whether or not application can be reversed to allow for other innovation options, overall change in profit to the farms from the innovation, how long it will take for the change in profit to take effect, whether or not the innovation decreases farmers' vulnerability to seasons with severe conditions, the advantages and disadvantages of the environment as a result of implementation, how long until the environmental effects are noticeable, and the non-monetary benefits of the innovation to the farmer. 


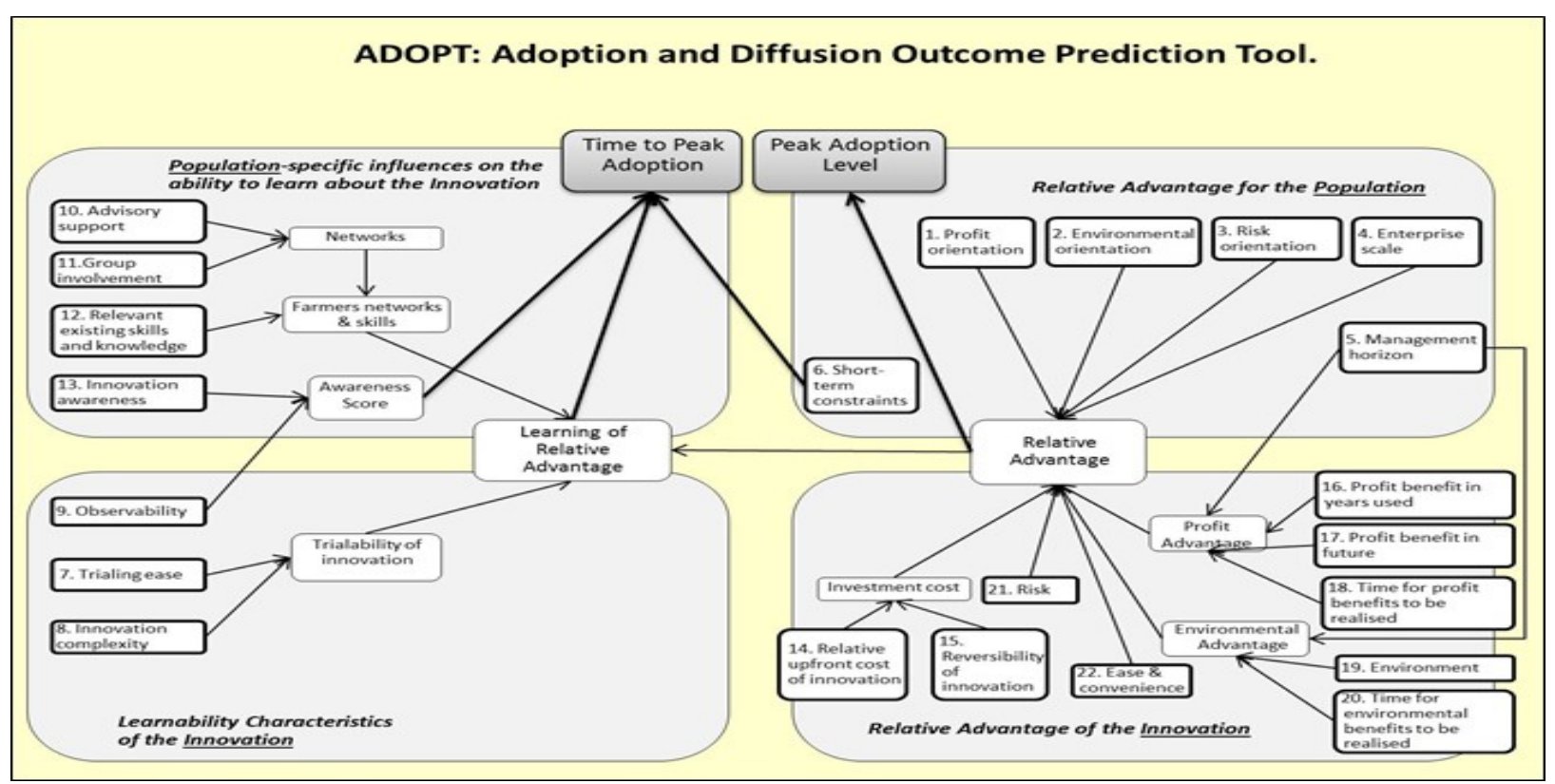

Figure 1. Adoption and diffusion outcome prediction tool framework (ADOPT)

Source: http://aciar.gov.au/files/node/13992/adopt_a_tool_for_evaluating_adoptability_of_agric_94588.pdf

\section{Results and Discussion}

The general assessment of the technologies introduced by the ICARDA-APRP indicates that AP farmers believed that the introduced technologies are useful for them. Farmers believe on the mentioned technologies because they fit very well with their climatic and socio-demographic conditions, they give high yield with less water, less pest, and consequently more benefit. Farmers prefer the technology with little input (mainly in labor and in the use of chemicals and pesticides) but with large interest, but ensuring high productivity. Farmers also prefer flexible and not sophisticated technology. They expect to have more knowledge and know-how through more efficient extension system and about some technologies such as soilless culture mainly the technical and commercial aspects.

In the section below, we present and discuss the results of the main findings related to the prediction of adoption levels of each technology in each studied country taking into consideration the main factors that could influence the adoption and dissemination of these techniques.

\subsection{Predicted Adoption Levels and Factors Affecting the Adoption of Soilless Production System (SS) Technology (Technology II)}

Regarding the adoption of the soilless production systems (Technology I), the results of the FGD with farmers in Bahrain, Kingdom of Saudi Arabia (KSA), Qatar, and Yemen showed that the peak adoption rate for this technology is predicted to be at $95 \%, 91 \%, 8 \%$ and $86 \%$ after $17.5,18.3,19.2$ and 18.5 years, respectively (Figure 2). In Oman, the findings indicate a slight difference between the regions on the predicted level of the soilless production system. This difference is due to the socio-demographic and economic conditions of the growers and the farming system practiced in each region (Figure 3).

According to factors affecting the adoption curves (Figure 4), on both the peak of adoption and the time to reach this peak, results from the sensitivity analysis indicate that trialability of the technology in addition to its complexity considered as the main issues constraining the widespread of such technology for the studied countries. Nevertheless, in Bahrain, the adoption of the soilless system is affected negatively by the fact that it is not observable by the farmers who are yet to adopt it when it is used in their area. 


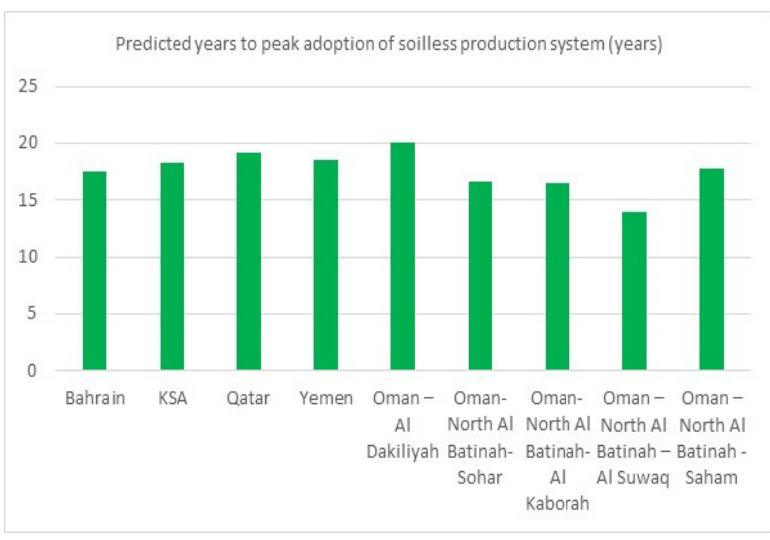

Figure 2. Predicted years to peak adoption of soilless production system (years)

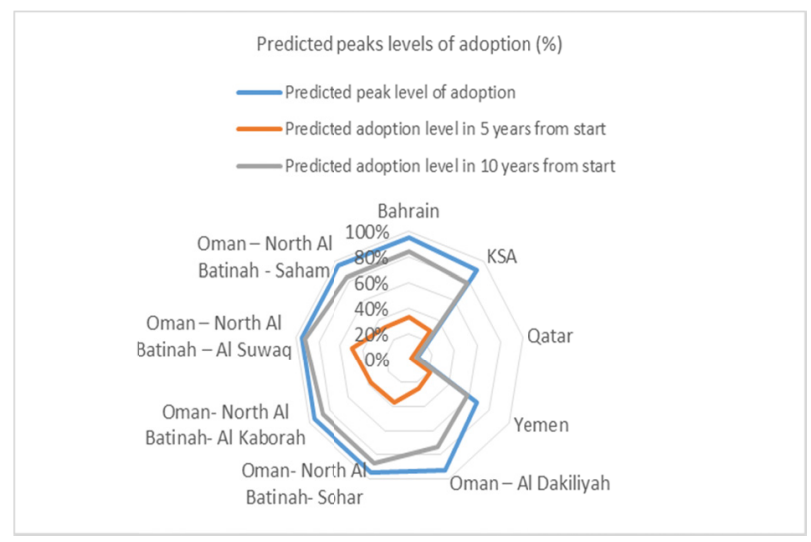

Figure 3. Predicted peaks levels of adoption of soilless production system $(\%)$

Source: Own elaboration from focus group data (2017).

In Yemen, in addition to the factors mentioned above, three factors are unique to the Yemeni growers that affect the adoption of the considered technology. Such factors are the risk, investment cost, and its profitability in the years that is used. In Qatar, some additional factors such as the need to develop strong new skills and knowledge to use the innovation were observed. This factor influence also the time to peak the adoption of soilless in Oman (including the regional adoption). This result highlighted the need to enhance the agriculture system to provide technical assistance for the users of this technology in all the regions.

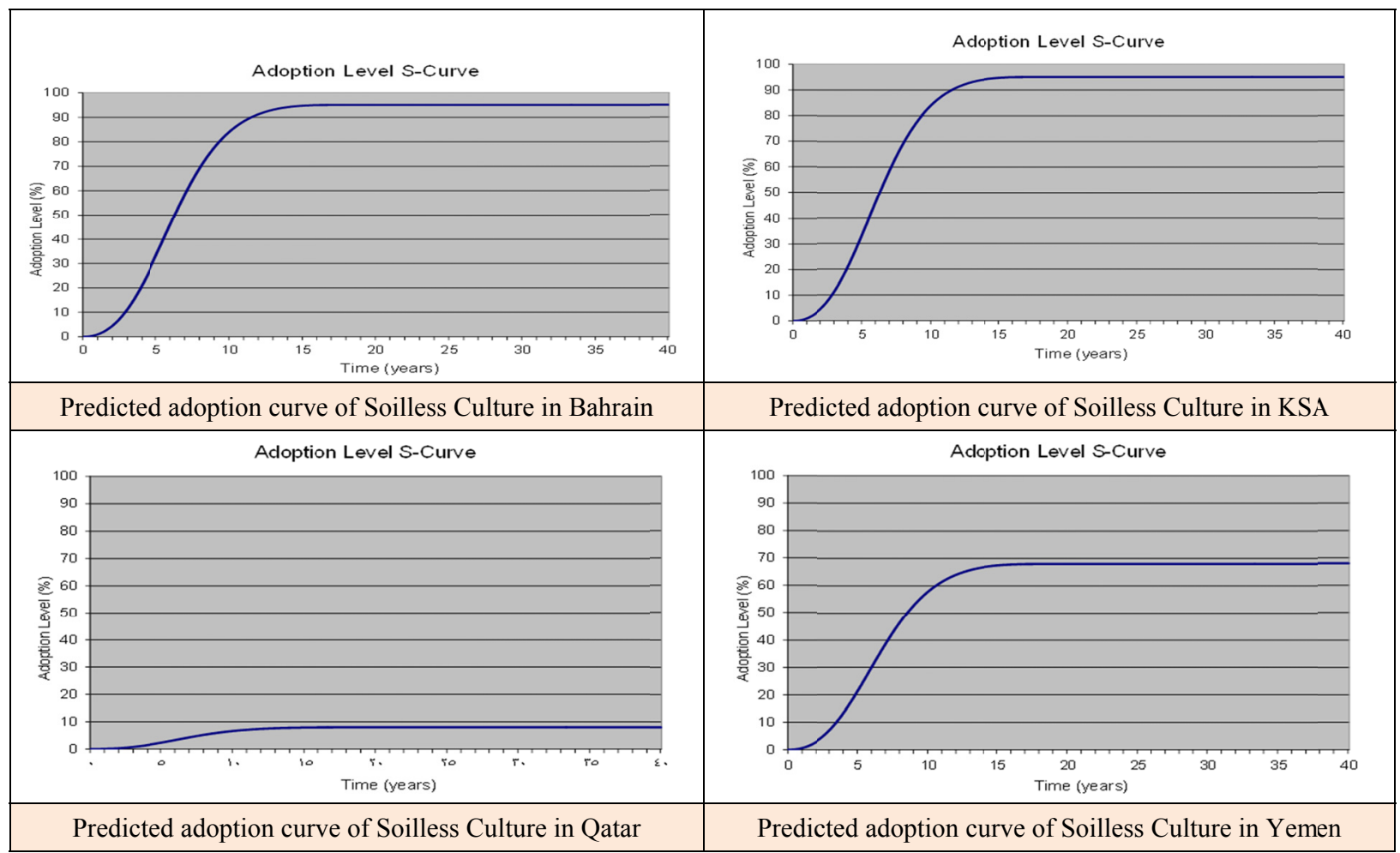




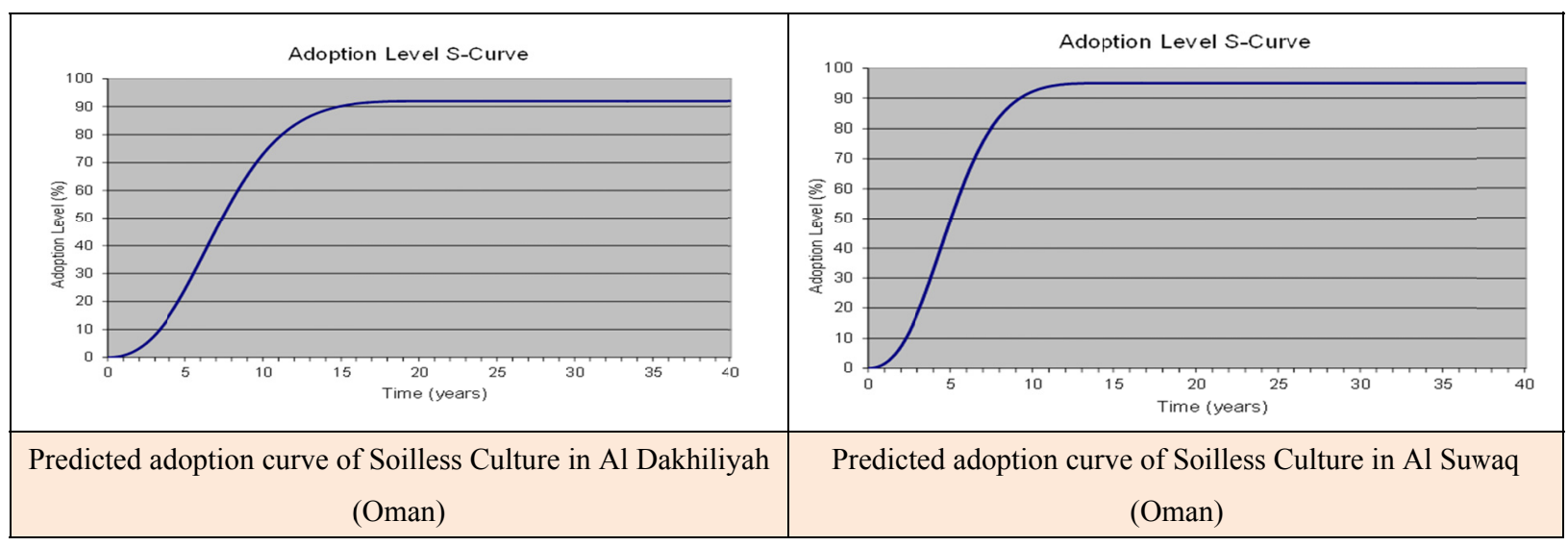

Figure 4. Adoption level S-Curve for soilless production culture in Bahrain, KSA, Qatar, Yemen and Oman

Source: Own elaboration from focus group data (2017).

\subsection{Predicted Adoption Levels and Factors Affecting the Adoption of Integrated Production and Protection Management (IPPM) Techniques (Technology II)}

One of the primary objectives of the ARPR is to include the IPPM. This technology package aims to reduce costs, increase the productivity of small farmers, and protect the environment by reducing the use of chemicals and pesticides. The assessment results of the adoption of this technology with particular emphasis on the main constraining factors affecting its adoption are displayed in Figure 5. Results showed the peak adoption rate for Bahrain, KSA, and Yemen for this technology is predicted to be $95 \%, 94 \%$ and $85 \%$ after a period of $11.2,21.6$ and 13.8 years, respectively (Figure 4). After five years from the start, the predicted adoption level is quite acceptable for Bahrain and Qatar against KSA where this predicted level is very low. Furthermore, this level remains low after ten years from the start of the adoption. This could be explained by the fact that many constraints are prohibiting the adoption and affect mainly the time to peak adoption level (Figure 6).

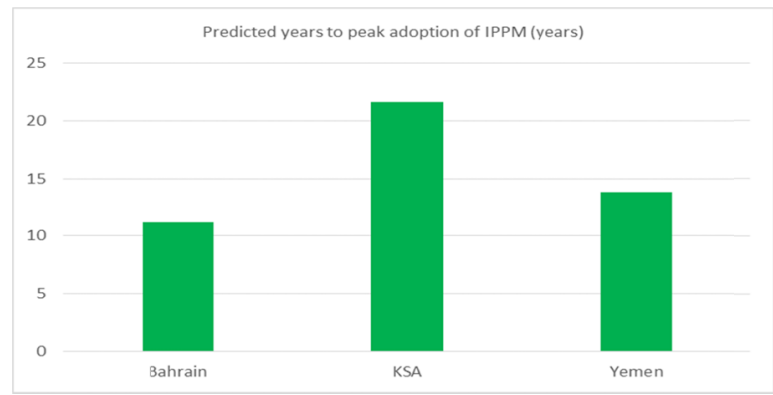

Figure 5. Predicted years to peak adoption of IPPM (years)

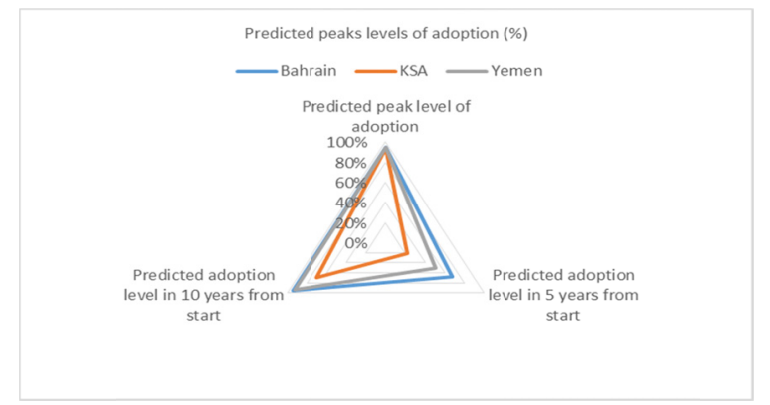

Figure 6: Predicted peaks levels of adoption of IPPM (\%)

Source: Own elaboration from focus group data (2017).

The discussion with farmers reveal that short-term financial constraints of the peasants, the trialability of the technology, lack of a relatively active national technical advisory service, and the up-front cost relative to the potential annual benefit from using this IPPM technology are the major constraints of adoption and dessimination of this trechnology package. The outlined factors are also raised by the Yemeni farmers. Thus, for further expansion of this technology, there is a need for an enabling environment policy enhancing the use of organic sources and reducing the utilization of the chemical in the indicated countries. Indeed, these factors are the primary drivers that could affect the adoption curves of the IPPM techniques (Figure 7). 


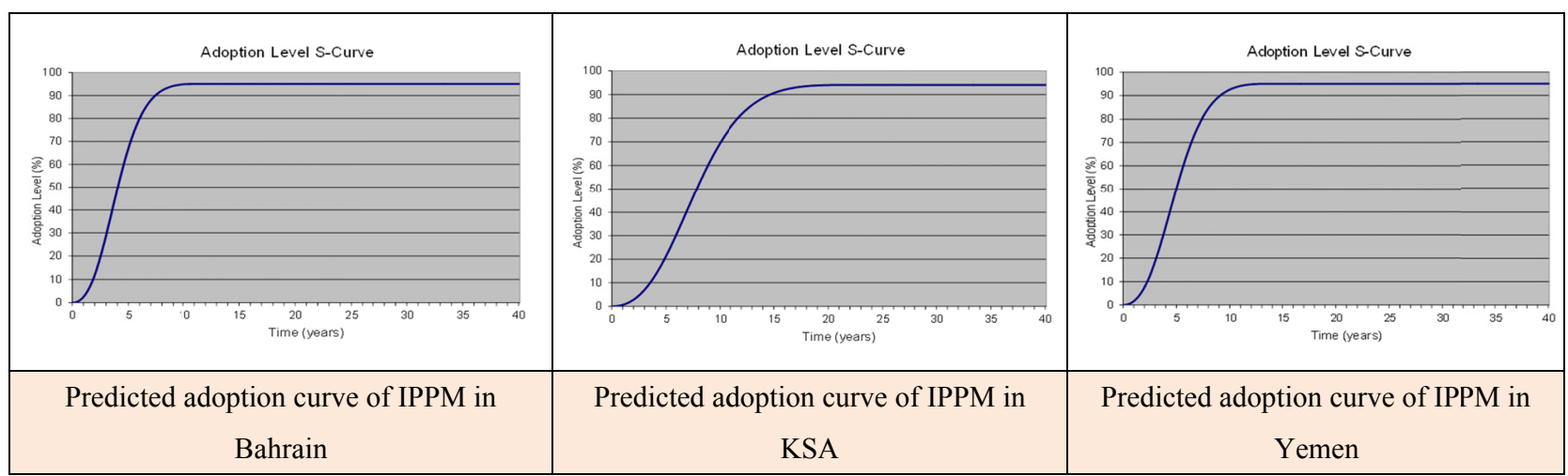

Figure 7. Adoption level S-Curve for IPPM technology in Bahrain, KSA, and Yemen

Source: Own elaboration from focus group data (2017).

\subsection{Predicted Adoption Levels and Factors Affecting the Adoption of Irrigated Forages (IF) Technology (Technology III)}

The irrigated foraged and on-farm water management is an integrated technology introduced by the progroam, and it is considered as a proven technology given its profitability both economically and environmentally. The aim is to reduce the quantity of water used for irrigation and to increase the profitability of the animal production for the small farmers. Empirical findings from the identification and the analysis of the factors leading to the adoption of this technology, with emphasis to the predicted level of adoption and the time to peak such adoption after five and ten years from the start are presented in Figure 8. Figure 9 shows a similarity in the years to peak adoption in KSA, Qatar, and Yemen (for Clitoria forage) where this peak $(95 \%)$ is expected to be after 13.5, 14.6 and 13.2 years, respectively. In the case of Yemen (buffel grass forage), this peak is predicted to be after 17.3 years.

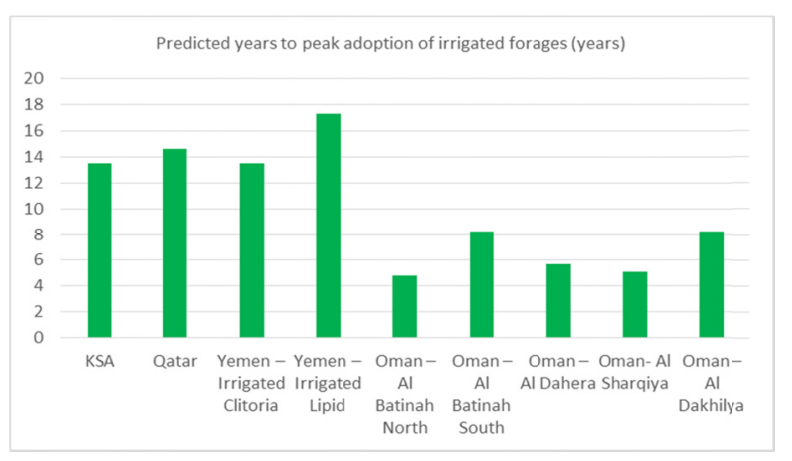

Figure 8. Predicted years to peak adoption of irrigated

$$
\text { forages (years) }
$$

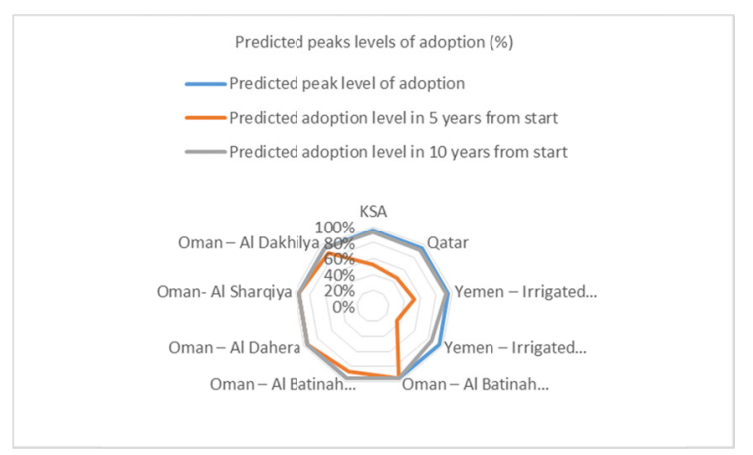

Figure 9. Predicted peaks levels of adoption of irrigated forages $(\%)$

Source: Own elaboration from focus group data (2017).

In Oman, we note that this peak is very short in comparison with the rest of AP countries. It is expected to be around five years from the northern region and between six and eight years for the south of the country (Figure 10). This variability is because natural environment of the north area of Oman is characterized by significant water and animal resources which enhance the adoption of this technology.

The results indicate that some factors influence the extent of adoption of technology such as characteristics or attributes of technology; financial factors, the change agent (extension system, professional, etc.); and the socioeconomic and physical environment in which the technology take place. Thus, it is imperative to create favorable conditions so that a greater number of farmers can make use of these techniques. Furthermore, on the most important steps towards this goal is to identify the factors encouraging the adoption of high water efficiency irrigated forages. 


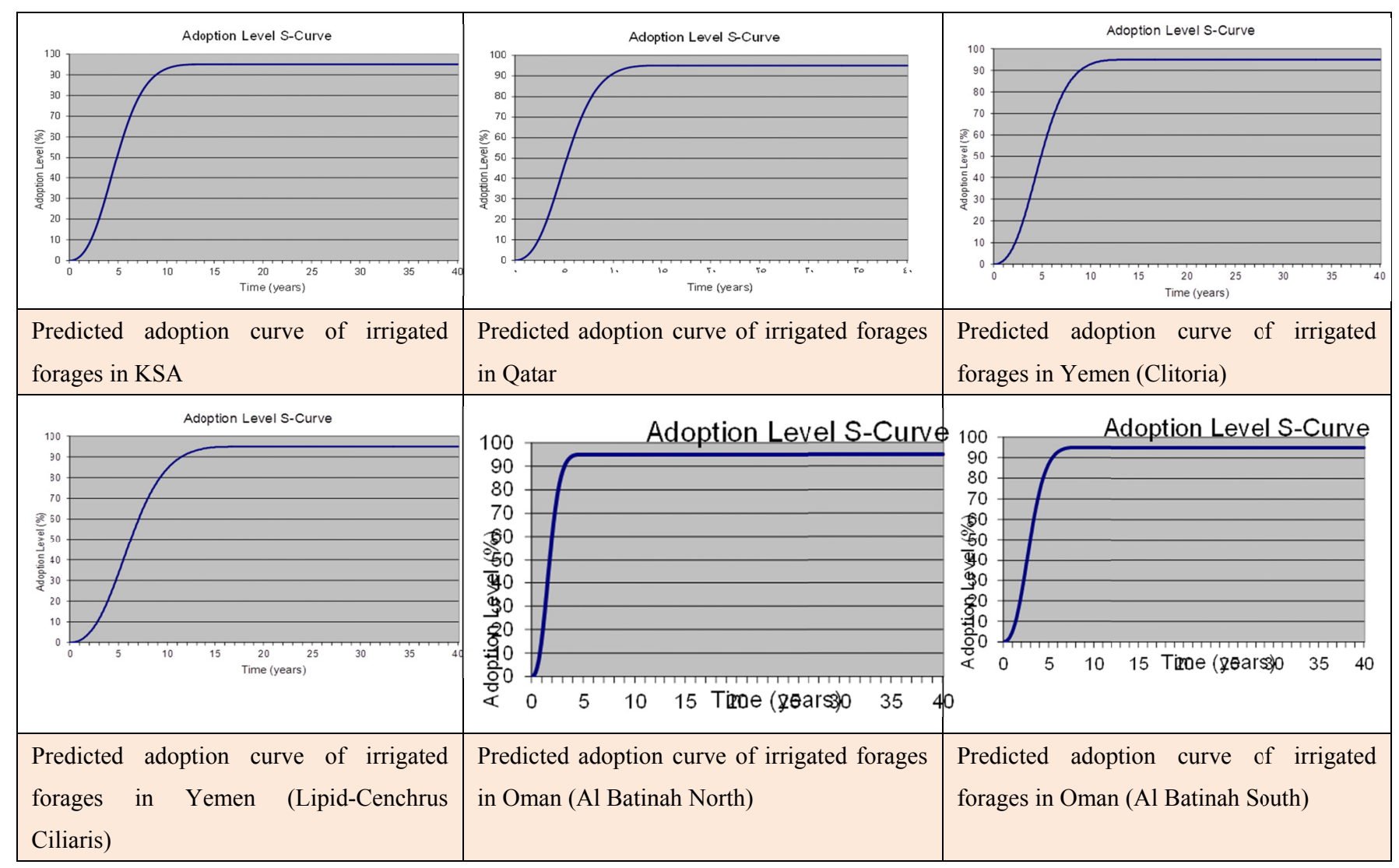

Figure 10. Adoption level S-Curve for irrigated forage technology in KSA, Qatar, Yemen and Oman

Source: Own elaboration from focus group data (2017).

The results displayed in Figure 10 leads to confirm that factors such as severe short-term financial constraints, trialability of the technology before a decision is made to adopt it, complexity of the technology, observability to farmers who are yet to adopt it when it is used in their area, paid advisors capable of providing advice relevant to the innovation, need to develop substantial new skills and knowledge to use the innovation, and the size of the up-front cost of the technology relative to the potential annual benefit from using it. Thus, the farmer's skills and networks, the trialability of the innovations, combined with the relative advantage of the innovations make up the population's ability to learn about the innovations, and this coupled with the factor of short-term financial constraints determines the time to peak adoption. In these countries, increasing farmers' knowledge and perception of the merits of irrigated less water consuming forages technology through better access to technical information, extension, and training is often cited as central to helping them on developing a positive assessment of this proven and promising technology. However, any intervention should take into consideration the most important influencing adoption factors, region specificities and farmers' preference.

\subsection{Predicted Adoption Levels and Factors Affecting the Adoption of Spineless Cactus (SC) Technology (Technology IV)}

The peak adoption rate for the adoption of spineless cactus in Qatar is predicted to be $95 \%$ after a period of 9.4 years (Figure 11). The predicted adoption level in five and ten years from the starting time of the adoption of this technology is 80 and $90 \%$, respectively (Figure 12). The peak adoption for this technology package is predicted to be relatively high according to the factors such as the farmers' and environmental profit, low-risk orientations, the number of farmers expected to benefit from the innovations, and the easiness and convenience of implementation and use. 


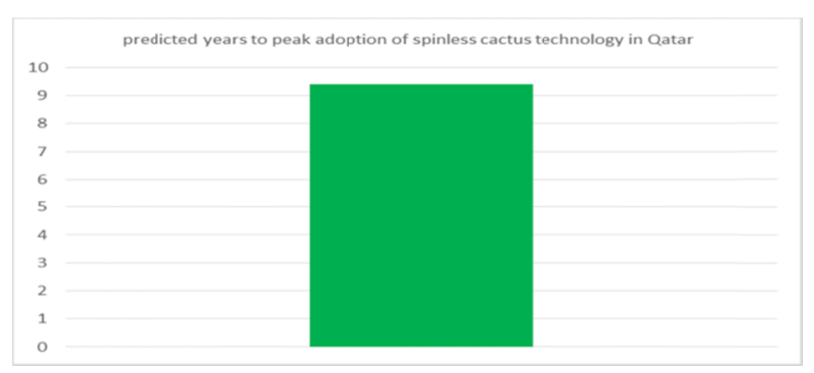

Figure 11. Predicted years to peak adoption of spineless cactus in Qatar (years)

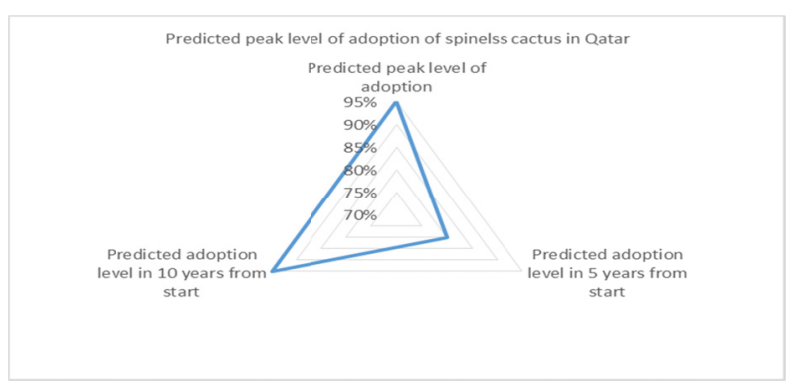

Figure 12. Predicted peak level of adoption of spineless cactus in Qatar (\%)

Source: Own elaboration from focus group data (2017).

The farmer's skills and networks, and the trialability of the innovations, combined with the relative advantage of the changes make up the population's ability to learn about the innovations. These factors determine the time to peak adoption (Figure 13). This results suggested the expected adoption of this technology in the future is quite promising and therefore, its scaling-up should be accompanied by an efficient and specialized extension system and an enabling policy environment in addition to a supporting financial system given the high cost of rehabilitation.

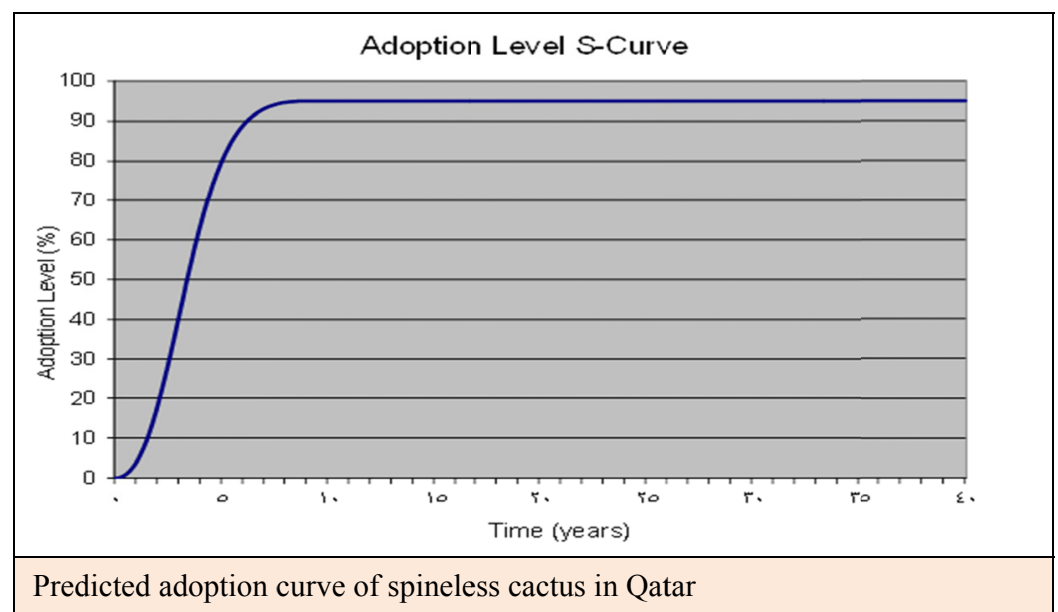

Figure 13. Adoption level S-Curve and Sensitivity Analysis (Peak and time to peak adoption level) for Spineless Cactus Technology in Qatar

Source: Own elaboration from focus group data (2017).

\subsection{Predicted Adoption Levels and Factors Affecting the Adoption of Rangeland Rehabilitation (RR) Technology (Technology $V$ )}

The analysis of the empirical findings presented in Figure 14 related to the predicted level of adoption for the rangeland rehabilitation technology indicates a huge difference between KSA and Qatar on the predicted peak of adoption of this technology. Although the predicted years to peak such adoption are around 18 years, the peak of adoption is expected to be $92 \%$ for KSA and $11 \%$ for Qatar (Figure 15). This predicted peak remains very low even during the first five and ten years for the case of Qatar. 


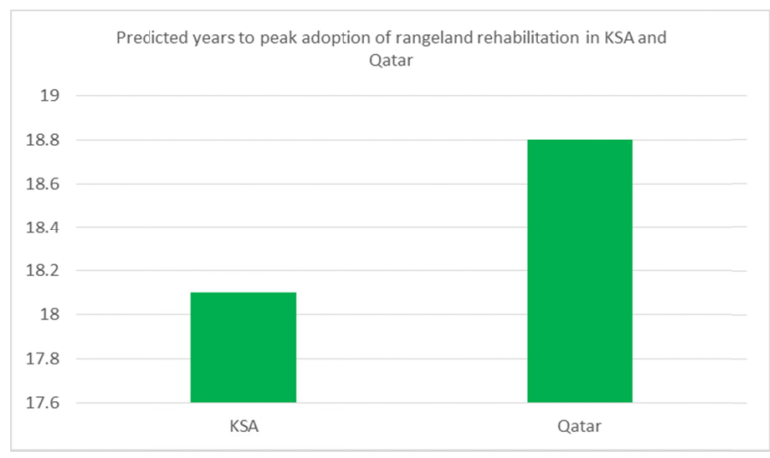

Figure 14. Predicted years to peak adoption of rangeland rehabilitation in KSA and Qatar (years) Source: Own elaboration from focus group data (2017).

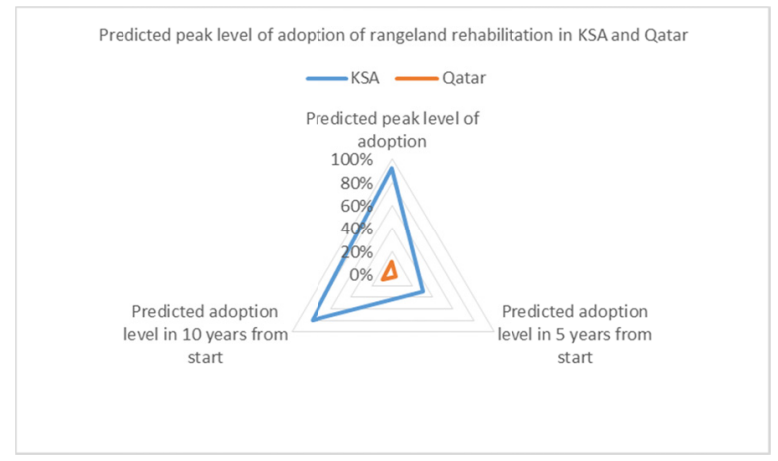

Figure 15. Predicted peak level of adoption of rangeland rehabilitation in KSA and Qatar (\%)

The sensitivity analysis reveals that many factors are contributing/constraining to this peak level of adoption mainly for Qatar (Figure 15). These factors are the complexity of the innovation, the need for farmers to develop new skills and knowledge to adapt the innovation and support the government strategy, and also the problem linked to the up-front cost of the investment in comparison with the potential delayed benefit from using this technology. This implies that decisions makers should take into account, from one hand, providing the farmers and herders with incentives to improve land use practices, to ensure sustainability and reduced land fragmentation. Thus, support and develop the rangelands sector in KSA and Qatar as to attain a sustainable development and increased productivity and preserve achievements, and enhance the integrative role of concerned parties and participation of local communities through participatory approach and community based rangeland rehabilitation in natural resources management as to have improved standards of living in light of climate changes and recurrent droughts which have significantly aggravated the deterioration of natural resources and wild life. On the other hand, this includes the necessity to rangelands sustainable development and management; improvement of social and economic conditions for livestock breeders and pastoral communities taking into consideration gender issues; enhancement of capacity building (training and awareness); monitoring and evaluation of rangeland status, and engagement of Local communities in sustainable rangeland development and management.

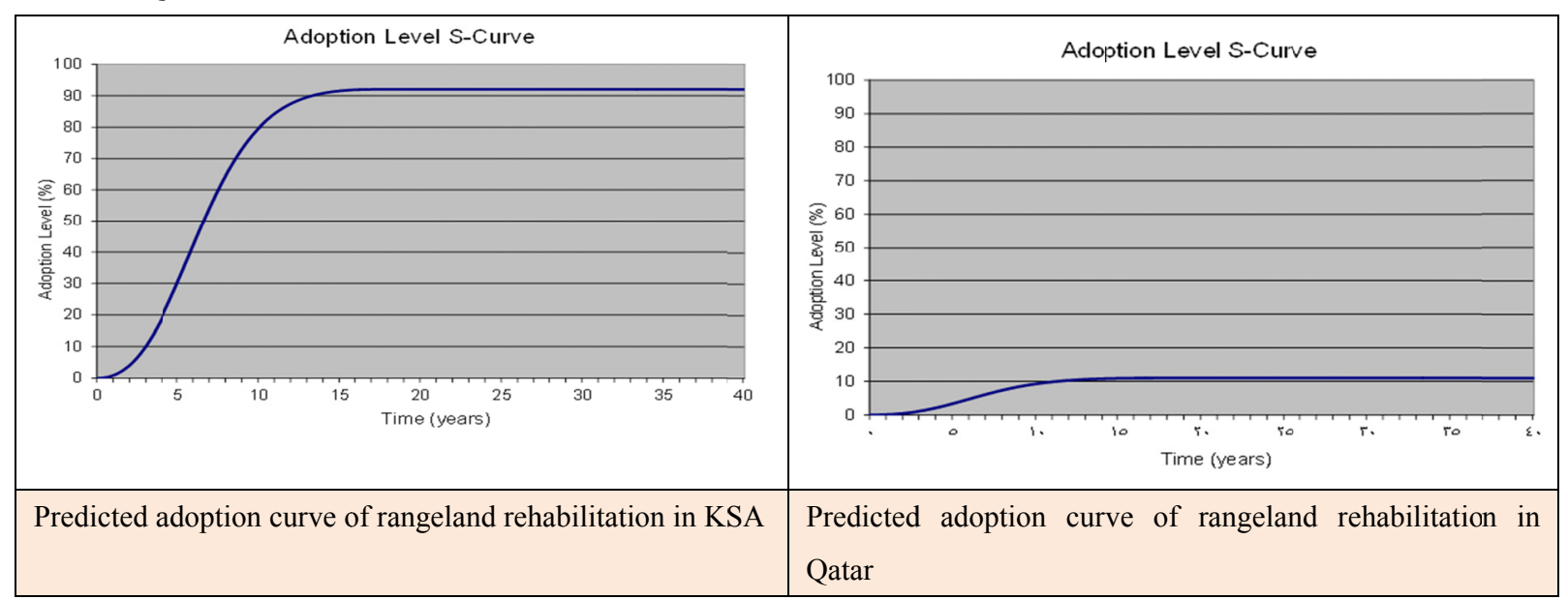

Figure 16. Adoption level S-Curve for rangeland rehabilitation in KSA and Qatar

Source: Own elaboration from focus group data (2017).

\section{Concluding Remarks and Policy Implications}

The economic evaluation and the identification and analysis of factors affecting ICARDA's Arabian Peninsula Regional Program (APRP) technologies implemented in the frame of the Improving food security and sustainable natural resources management through enhancing integrated agricultural production systems in the 
Arabian Peninsula project lead to the following results:

- There is a clear evidence on the economic profitability (reducing production costs and increase in net return) if these technologies are applied appropriately (case of Yemen). Indeed, farmers are encouraged to adopt these proven and promising technologies.

- The project research outputs proof that sustainable increase of vegetable crops and irrigated forages productivity can be achieved.

- The project research outputs also indicate that adopting of the Integrated Production and Protection Management (IPPM) and soilless production systems will contribute to a more environmentally friendly and water use efficient farming system.

- Although the complexity of some technologies (case of rangeland management system), there is a willingness from farmers/growers to adopt them.

- The predicted level of peak adoption of these technologies is different between the AP countries and within the same country (case of Oman).

- The characteristic of the technology is a determinant of its level and time to peak adoption level (low predicted the level of adoption for the irrigated forages and high predicted level of adoption for the IPPM and rangeland rehabilitation).

- Technical assistance, new skills, initiate cost of investment, financial resources, and efficient extension advisory services are considered the main factors influencing the adoption of these technologies.

- Take actions regarding these factors will only affect the time to reach the peak adoption levels of the targeted technologies.

The results of the present research study suggest the following:

- Given these technologies meet the technical, economic, and socioeconomic requirements, there is a need for a greater political and institutional input into these technologies. In particular, there is a need to design and develop alternative policy instruments (other than subsidies) and institutions for a well-developed agricultural extension system that will facilitate the adoption of APRP targeted technologies. There is a need also to create new price policy that gives higher prices for the IPPM products (or organic products). Furthermore, raising awareness of farmers and decision makers on the environmental benefits by applying these technologies is needed to gain their support and confidence.

- The benefits (economic and ecological) of these technologies must be clearly perceived by farmers, given their own socioeconomic, cultural and economic conditions. In AP, increasing farmers' knowledge and perception of the merits of these technologies through better access to technical information, know-how, effective extension delivery system, credit services, and training will help them to develop a positive assessment of these technologies. This is indeed will ensure their scaling-up and widespread use.

- To accelerate the adoption process of these technologies, creating favorable conditions is important so that a greater number of farmers can take advantage of the benefits of such technologies. Creation of an effective networking among different institutions related to applying ICARDA-APRP technologies and involvement of public and private financial institutions and support services could be an example of mechanisms to enhance adoption. More specifically, linking mechanisms between research and extension and extension education on ICARDA-APRP technologies would further push the adoption of such resource-saving technologies at the farm level.

- Finally, there is an apparent disparity at the regional scale on the degree of adoption and on the factors affecting and encouraging the adoption of a specified technology (i.e. case of the soilless production system and irrigated forage in Oman). Thus, scaling up to another region within the same country could be facilitated with interactive similarity maps that identify similar socio-economic and environmental contexts. Hence, only technologies with a high financial feasibility should be promoted, and therefore farmers should be encouraged to join established and strengthened associations through which training, technical assistance, and help with access to extension information can be provided. The policy implication that emerges from this finding is that action can only be achieved through planned and designed programs in partnerships with all concerned organizations and targeting the right beneficiaries.

\section{Acknowledgements}

The authors would like to acknowledge the dedication, hard work and support of the management, researchers 
and scientists of the national research and extension systems of Arabian Peninsula countries.

ICARDA is deeply grateful to the donors of the Arabian Peninsula Regional Program- the Arab Fund for Economic and Social Development (AFESD), the International Fund for Agricultural Development (IFAD) and the OPEC Fund for International Development (OFID) - for their interest, encouragement and the highly valued financial support. Their care and consideration were a major force behind the success of this program.

\section{Declarations of conflict of interest}

The authors report no declarations of conflict of interest.

\section{References}

Feder, G., Just, R., \& Zilberman, D. (1985). Adoption of agricultural innovations in developing countries: A survey. Ec. Dev. Cul. Cha., 33(2), 255-298. https://doi.org/10.1086/451461

Griliches, Z. (1957). Hybrid corn: An exploration in the economics of technological change. Econ., 25, 501-522. https://doi.org/10.2307/1905380

Krueger, R. A. (2002). Analysis: Systematic Analysis Process. Retrieved November 12, 2016, from www.tc.umn.edu/ rkrueger/focus_analysis.html

Kuehne, G., Llewellyn R., Pannell, D., Wilkinson, R., Dolling, P., \& Ouzman, J. (2013). ADOPT: the Adoption and Diffusion Outcome Prediction Tool (Public Release Version 1.0, June 2013) [Computer software] Adelaide SA; CSIRO. Retrieved from www.csiro.au/ADOPT

Marra, M., \& Carlson, G. (1987). The role of farm size and resource constraints in the choice between risky technologies. W. J. Ag. Eco., 12(2), 109-118.

Mazahrih, N., Al-Wahaibi, H., Al-Farsi, S., \& Ouled Belgacem, A. (2016). Yield and water productivity of Buffel and Rhodes grasses under different irrigation water regimes using the sprinkler line-source system. Gras. Sc., 62(2), 112-118. https://doi.org/10.1111/grs.12120

NCB Capital. (2010). Economic Research, 28p. Retrieved October, 2016, from

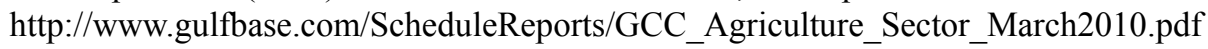

Rahm, M., \& Huffman, W. (1984). The adoption of reduced tillage: The role of human capital and other variables. Am. J. Ag. Eco., 66(4), 405-413. https://doi.org/10.2307/1240918

Rogers, E. (1995). Diffusion of innovations (4th ed.). New York: The Free Press.

\section{Notes}

Note 1. All information concerning how ADOPT works was found at: http://aciar.gov.au/files/node/13992/adopt_a_tool_for_evaluating_adoptability_of_agric_94588.pdf

\section{Copyrights}

Copyright for this article is retained by the author(s), with first publication rights granted to the journal.

This is an open-access article distributed under the terms and conditions of the Creative Commons Attribution license (http://creativecommons.org/licenses/by/4.0/). 